\title{
Gust Response and Body Freedom Flutter of a Flying-Wing Aircraft with a Passive Gust Alleviation Device
}

\author{
$\mathrm{S} \mathrm{Guo}^{1}, \mathrm{ZW} \mathrm{Jing}^{1,2}, \mathrm{H} \mathrm{Li}^{1}$, WT Lei ${ }^{2}$, YY $\mathrm{He}^{3 \dagger}$ \\ ${ }^{1}$ Centre for Aeronautics, Aerospace, Cranfield University, Cranfield, Beds, UK \\ ${ }^{2}$ The First Aircraft Institute, AVIC, Xian, China \\ ${ }^{3}$ School of Aerospace Engineering, Beijing Institute of Technology, Beijing, China
}

\begin{abstract}
The effectiveness of a passive gust alleviation device (PGAD) mounted at the wingtip of aircraft in conventional and flying-wing configurations have been studied in previous research. However the PGAD influence on the aeroelastic stability in particular the body freedom flutter (BFF) of a flying-wing aircraft remains as a concern. This present investigation is focused on evaluating the beneficial effect of PGAD on both gust load alleviation and BFF of a small flying-wing aircraft of high aspect ratio wing made of composite. A small range of (1-cos) type of gust load has been considered to select a representative critical gust load case for the study. A parametric study indicates that there is a narrow band of optimal key parameters for the PGAD design. Subsequently a set of optimal parameters is selected to further the analysis of the PGAD mechanism. The case study results show that the PGAD can make the bending moment at the wing root due to gust reduced by $16 \%$. In addition, the BFF speed of the flying-wing aircraft is increased by $4.2 \%$. The investigation reveals that the PGAD mode and its interaction with the wing bending mode and short period oscillation of the aircraft can have beneficial aeroelastic effect on both gust alleviation and flutter suppression.
\end{abstract}

Key words: flying-wing aircraft, passive gust alleviation device, gust response, body freedom flutter.

\section{Nomenclature}

$\boldsymbol{M}, \boldsymbol{D}, \boldsymbol{K}=$ the mass, damping and stiffness matrix of the aircraft structure respectively;

$\boldsymbol{x} \quad=$ the special displacement vector of the aircraft structure;

$\boldsymbol{F}_{\mathrm{A}}, \boldsymbol{F}_{g} \quad=$ the unsteady aerodynamic force vector due to dynamic motion and gust load;

$\boldsymbol{q} \quad=$ generalized displacement;

$\overline{\boldsymbol{M}}, \overline{\boldsymbol{D}}, \overline{\boldsymbol{K}}=$ generalized mass, damping and stiffness matrix of the wing structure respectively;

$\bar{Q} \quad=$ generalized aerodynamic force matrix;

$\Phi=$ = normal mode matrix of the aircraft structure;

$q^{*} \quad=$ the aerodynamic dynamic pressure;

$\Delta \boldsymbol{p}=$ aerodynamic pressure on the lifting surface element panel

$\boldsymbol{C}_{A}, \overline{\boldsymbol{w}}=$ aerodynamic influence coefficient matrix and downwash on the lifting surface element;

\footnotetext{
† Corresponding author: appleyuanyuan@bit.edu.cn
} 


$$
\begin{aligned}
& A, b \quad=\quad \text { the reference area and reference semi-chord of the wing; } \\
& U, U_{\mathrm{de}} \quad=\text { gust velocity and design (derived) gust velocity according to CS-VLA; } \\
& L_{g}, S \quad=\text { gust gradient and the distance of aircraft penetrating into the gust profile; } \\
& f_{g}, k_{g}=\text { equivalent gust frequency }(\mathrm{Hz}) \text { and gust alleviation factor respectively; } \\
& c, \bar{C} \quad=\text { local geometric chord and mean chord of the wing. } \\
& C_{\mathrm{L}}, C_{\mathrm{L} \alpha}=\text { lift coefficient and derivatives of the wing } \\
& C_{\mathrm{m}}, C_{\mathrm{m} \alpha}=\text { pitching moment coefficient and derivatives of the wing } \\
& C_{\mathrm{Lq}}, C_{\mathrm{mq}}=\text { derivatives of the lift and pitching moment coefficients to pitch angular velocity; } \\
& V_{\mathrm{c}}, V_{\mathrm{D}} \quad=\text { cruise speed and dive speed respectively; } \\
& V_{\mathrm{f}}, f_{\mathrm{f}} \quad=\text { flutter speed and frequency respectively. }
\end{aligned}
$$

\section{Introduction}

In aircraft design, various active and passive gust alleviation technologies have been developed including the classical active control [1-4] and passive control methods [5-6]. The gust response of an aircraft of high aspect ratio wing is sensitive to the engine placement [7]. Some of the studies of particular interest include the aeroservoelastic analysis of B2 bomber [8], and the wingtip device of discrete and raked options for gust load alleviation [9]. In the last decade, the feasibility of a novel passive gust alleviation device (PGAD) has been investigated for unmanned and large civil aircraft [10-12]. The PGAD is mounted at the wingtip of a flying wing aircraft through a shaft and elastic hinge as illustrated in Fig.1. In the previous research, a parametric study of the PGAD was performed to determine the rotation stiffness and the shaft location in front of the aerodynamic center. The PGAD will twist nose down in response to a vertical gust excitation to alleviate the excessive aerodynamic force. The results indicated that a significant reduction of gust response in terms of wing deflection and bending moment was achieved. For an aircraft of tailless flying-wing configuration however, the flight stability control and body freedom flutter (BFF) are two critical concerns, which has been studied before [13-15]. The USAFRL sponsored BFF research program since 2005 has led to the demonstration of active control technology for BFF suppression and gust load alleviation of the flying-wing UAV X-56A. Similar to the X-56A, the wingtip section of a flying-wing aircraft with large swept angle and high aspect ratio wing plays a mixture role of aileron and tail-plane. When the PGAD is employed, the wingtip section becomes a flexible control surface of the mixed functions. When facing a vertical gust load, the PGAD will twist nose down like an aileron to reduce the gust induced aerodynamic force on the wing. In the same time, the negative twist of the PGAD will produce a positive pitching moment on the aircraft like a tail-plane function. This results in an 
increase of angle of attack of the aircraft and consequently aerodynamic force on the whole flyingwing aircraft. An optimal PGAD design will lead to a balanced rotation together with the wing twist due to static aeroelastic effect. On the other hand, the PGAD raises an additional uncertainty and concern on the aircraft aeroelastic stability in particular the BFF. This project is aimed to investigate the PGAD function for gust response reduction and BFF suppression of a flying-wing aircraft.
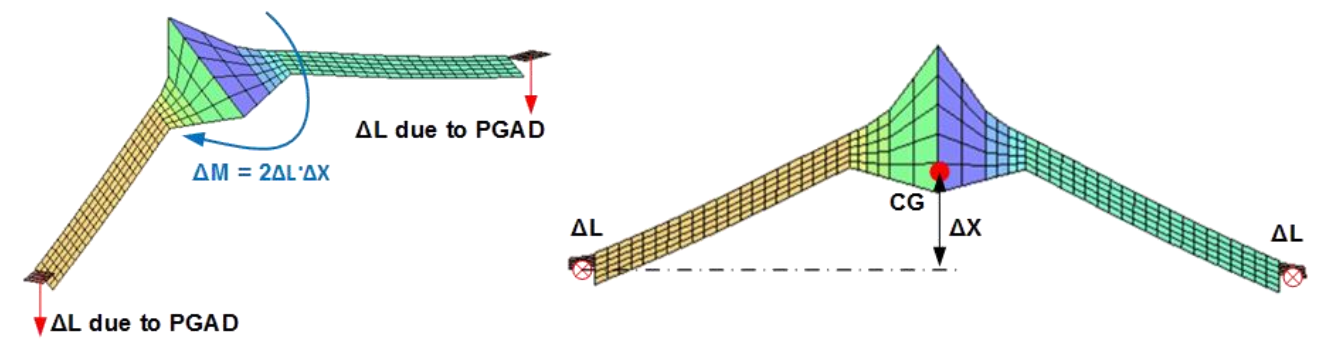

Figure 1. PGAD mounted at the wingtip of a flying-wing aircraft

The wing structure made of laminated composite is modelled using FEM; the aerodynamic analysis using doublet-lattice method; the aeroelastic analysis using P-K method based on normal mode in frequency domain respectively. The gust induced external aerodynamic force and response was based on the 1-cosine discrete gust model. In this study, the main concern is the relative gust response of an aircraft with the PGAD comparing with the baseline aircraft gust response without PGAD. Based on the modelling and analysis, a parametric study of the PGAD is carried out to determine the optimal design parameters for minimum gust response and maximum BFF speed. Taking a flying-wing aircraft model as a case study, the effectiveness of the PGAD is demonstrated by a significant reduction of the gust induced bending moment at the wing root. The optimal PGAD also makes beneficial contribution to the coupling between the short period oscillation and wing bending modes of the aircraft that leads to an increase of the BFF speed.

\section{Analytical and Numerical Methods}

A general form of the governing equation for aeroelastic analysis is expressed below.

$$
M \ddot{x}+D \dot{x}+K x=F_{\mathrm{A}}+F_{\mathrm{g}}
$$

where $\boldsymbol{M}, \boldsymbol{D}$ and $\boldsymbol{K}$ represents the mass, damping and stiffness matrix of the aircraft structure respectively; $\boldsymbol{x}$ represents the special displacement vector; $\boldsymbol{F}_{\mathrm{A}}$ and $\boldsymbol{F}_{g}$ represents the unsteady aerodynamic force vector due to dynamic motion and gust load input. Since the PGAD is part of the wing structural, it is modelled as part of the $\boldsymbol{M}$ and $\boldsymbol{K}$ and also included in the $\boldsymbol{F}_{\mathrm{A}}$ and $\boldsymbol{F}_{\mathrm{g}}$ calculations. By employing the normal mode method and generalized coordinate $\boldsymbol{q}$ into Eq.(1) to replace the $\boldsymbol{x}=\boldsymbol{\phi q}$, the governing equation can be transferred from time-domain to frequency-domain and expressed by 


$$
\overline{\boldsymbol{M}} \ddot{\boldsymbol{q}}+\overline{\boldsymbol{D}} \dot{\boldsymbol{q}}+\overline{\boldsymbol{K}} \boldsymbol{q}-q_{\infty} \overline{\boldsymbol{Q}} \boldsymbol{q}=\boldsymbol{\Phi}^{T} \boldsymbol{F}_{g}
$$

where $\overline{\boldsymbol{M}}, \overline{\boldsymbol{D}}$ and $\overline{\boldsymbol{K}}$ represent the generalized mass, damping and stiffness matrix of the wing structure respectively; $q_{\infty}$ is the dynamic pressure.

The unsteady aerodynamic force $\boldsymbol{F}_{\mathrm{A}}$ in the above equation is calculated using the Doublet-Lattice Method (DLM) built in the Nastran package. The aerodynamic pressure on the lifting surface element panels can be expressed in the following vector and matrix form,

$$
\Delta \boldsymbol{p}=\frac{1}{2} \rho V_{\infty}^{2} \boldsymbol{C}_{\mathrm{A}}^{-1} \overline{\boldsymbol{w}}
$$

where $\rho$ and $V_{\infty}$ represents the air density and flight velocity of the aircraft respectively; $\boldsymbol{C}_{\mathrm{A}}$ represents the aerodynamic influence coefficient matrix; $\overline{\boldsymbol{w}}$ represents the downwash on the collocation points of the panel. The generalized unsteady aerodynamics in frequency domain can be calculated by

$$
\overline{\boldsymbol{Q}}(k)=\boldsymbol{\phi}_{\mathrm{A}}^{\mathrm{T}} \boldsymbol{A} \boldsymbol{C}_{\mathrm{A}}^{-1}\left(i \frac{k}{b} \boldsymbol{\phi}_{\mathrm{c}}+\boldsymbol{\phi}_{\mathrm{c}}^{\prime}\right)
$$

where $\phi_{\mathrm{A}}$ and $\boldsymbol{\phi}_{\mathrm{c}}$ are the mode shape at the aerodynamic center and the downwash collocation point of the panel respectively; $b$ and $k=\omega b / V_{\infty}$ is the reference semi-chord and a reduced frequency.

In the present study, the rigid body mode is included and the gust load $\boldsymbol{F}_{\boldsymbol{g}}$ is removed when performing BFF analysis. In the generalized coordinate system, the number of modes can be selected by truncating the high order modes according to the dominating modes in gust response and flutter analysis. The size of the Eq.(2) can be reduced significantly to save computational time.

In aircraft design, the gust velocity based on a discrete 1-cosine gust profile is expressed below.

$$
U=\frac{U_{d e}}{2}\left(1-\cos \frac{2 \pi S}{2 L_{g}}\right)
$$

where $U_{\mathrm{de}}$ is design gust velocity, $L_{g}$ and $S$ is the gust gradient (distance) and the distance of aircraft penetrating into the gust. At cruise speed $V_{\mathrm{c}}$ for example, $S=V_{\mathrm{c}} t$ and the cosine term in Eq.(5) can be rewritten as $\cos \left(\frac{2 \pi V_{c} t}{2 L_{g}}\right)=\cos \left(f_{g} t\right)$ where $f_{g}=\frac{V_{c}}{2 L_{g}}$ is an equivalent gust frequency $(\mathrm{Hz})$.

For a large aircraft, a sufficient number of gust gradient distances in the range of $L_{g}=9 \sim 107 \mathrm{~m}$ must be investigated to find the critical response for each gust load quantity. In the current investigation however, a very light aircraft design should be incompliance with the CS-VLA airworthiness [16] where the gust model is specified below.

$$
U=\frac{U_{d e}}{2}\left(1-\cos \frac{2 \pi S}{25 \bar{C}}\right)
$$

where $\bar{C}$ is the mean geometric chord of the wing. The equivalent gust frequency $f_{g}=S / 25 \bar{C} \mathrm{~Hz}$. 
Based on the gust velocity, the generalized aerodynamic force acting on the wing due to the gust in Eq.(2) can be calculated from

$$
\boldsymbol{\phi}^{\mathrm{T}} \boldsymbol{F}_{\mathrm{g}}=\boldsymbol{\phi}^{\mathrm{T}} q_{\infty} \boldsymbol{A} \boldsymbol{a}_{\mathbf{1}} k_{g} \frac{U}{V}
$$

where $\boldsymbol{A}$ is the reference area of the wing; $\boldsymbol{a}_{1}$ is the lift curve slope of the wing; $k_{g}$ is a gust alleviation factor expressed below for the typical gust model shown in Eq.(6). [17]

$$
k_{g}=\frac{0.88 \mu}{5.3+\mu}
$$

where $\mu=\frac{2 m}{\rho A \bar{C} a_{1}}$ is the mass parameter in which $m$ is the mass of the aircraft.

\section{Analysis Results of the Baseline Flying-Wing Aircraft}

\subsection{The aircraft model and aerodynamic analysis}

The planform dimensions and payload location of the flying-wing aircraft model is illustrated in Fig. 2(a). An engine of pusher propeller is mounted in the central line near the neutral point (NP) at the rear body of the aircraft. For the baseline aircraft without PGAD, the wing structure and lifting surface continues as one piece from root to tip. Fig. 2(b) shows the mesh of distributed structural mass model of the aircraft including a wingtip section of length $0.287 \mathrm{~m}$ divided into six mass elements. For the original aircraft model, the mass of this particular wingtip section is $3.25 \mathrm{~kg}$ with the center of gravity (CG) located at $15 \%$ chord measured from the leading edge (LE) in the central line as illustrated in Fig. 2(b). The technical data of the aircraft model are listed in Table 1.

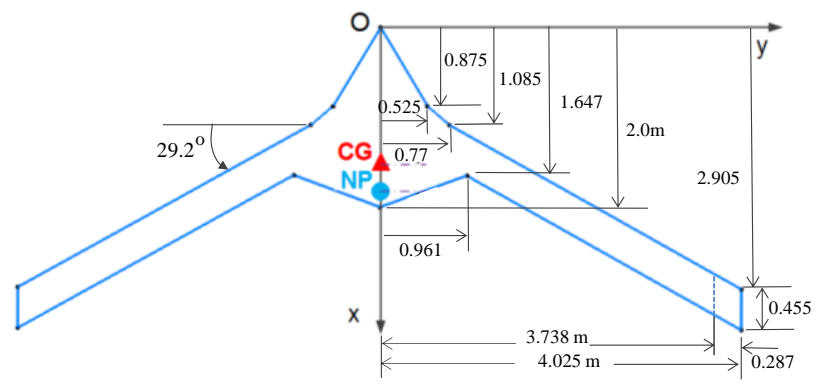

(a)

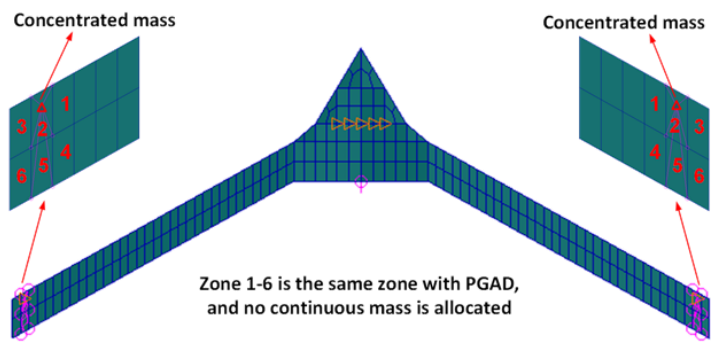

(b)

Figure 2 (a) the aircraft planform and dimension (b) and mass model

Table 1. Design technical data of the aircraft

\begin{tabular}{|c|c|c|c|c|c|c|c|c|}
\hline $\begin{array}{c}\text { Wing } \\
\text { span } \\
(\mathrm{m})\end{array}$ & $\begin{array}{c}\text { Aircraft } \\
\text { projected } \\
\text { area }\left(\mathrm{m}^{2}\right)\end{array}$ & $\begin{array}{c}\text { Sweep angle } \\
\text { of LE and } \\
\mathrm{TE}^{*}\left({ }^{\circ}\right)\end{array}$ & $\begin{array}{c}\text { Outer wing } \\
\text { chord (from } \\
y=0.96 \mathrm{~m})\end{array}$ & $\begin{array}{c}\text { Aircraft } \\
\text { empty } \\
\text { weight }(\mathrm{kg})\end{array}$ & $\begin{array}{c}\text { Payload } \\
(\mathrm{kg})\end{array}$ & $\begin{array}{c}\text { MTOW } \\
(\mathrm{kg})\end{array}$ & $\begin{array}{c}\text { Cruise } \\
\text { speed } \\
(\mathrm{m} / \mathrm{s})\end{array}$ & $\begin{array}{c}\text { Dive } \\
\text { speed } \\
(\mathrm{m} / \mathrm{s})\end{array}$ \\
\hline 8.05 & 4.92 & 29.2 & 0.455 & 109.9 & 20.2 & 130.1 & 30.0 & 40.0 \\
\hline
\end{tabular}

*leading edge (LE) and trailing edge (TE); § Maximum take-off weight (MTOW) 
For the selected wing airfoil NACA4415, the 3D steady aerodynamic calculation and trim analysis of the aircraft was carried out by using the Athena Vortex Lattice (AVL) method and program [18]. The mesh model of the aircraft was created as shown in Fig. 3(a). The aerodynamic lift and pitching moment coefficients $C_{\mathrm{L}}$ and $C_{\mathrm{m}}$ and the associated derivatives were calculated in a range of angle of attack (AoA) within $\pm 6^{\circ}$ and listed in Table 2 . The analysis results indicate that the aerodynamic force at $\mathrm{AoA}=1.87^{\circ}$ will meet the lift requirement for the aircraft maximum take-off weight (MTOW) at cruise speed $V_{\mathrm{c}}$ in sea level. The resulting aerodynamic lift distribution along the span of the aircraft is shown in Fig. 3(b). The aircraft center of gravity (CG) is located at $X=1.681 \mathrm{~m}$, which is $0.054 \mathrm{~m}$ in front of the aerodynamic center.

As revealed in previous research [19, 20], the effect of engine placement on the aeroelastic trim and stability of a flying-wing aircraft should be considered rather than only counter the total drag and engine's thrust. To simplify the stability analysis in the initial design, it is assumed that the aircraft is a rigid body and the engine thrust counteracts the total drag at cruise flight. The aircraft neutral point (NP) is set in line with the aerodynamic center. The resulting longitudinal static margin is $8.8 \%$ for the flying-wing aircraft.

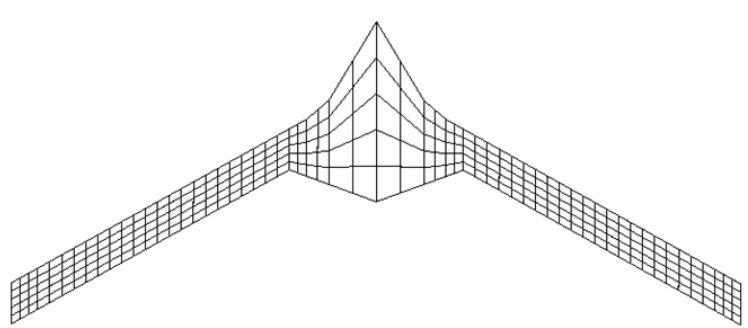

(a)

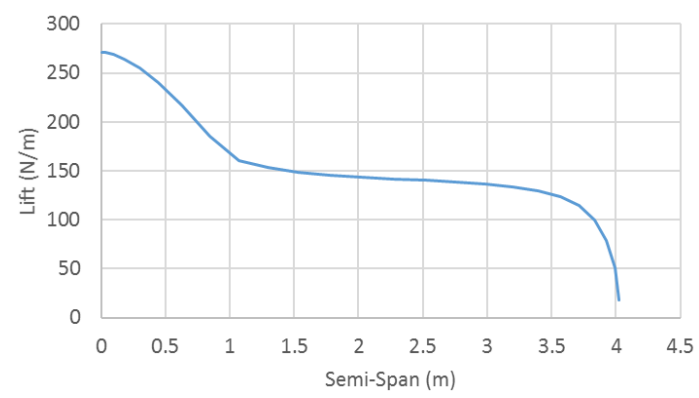

(b)

Figure 3. (a) Aerodynamic model mesh (b) spanwise lift distribution in level flight $\left(A o A=1.87^{\circ}\right)$

Table 2. Aerodynamic derivatives of the baseline aircraft

\begin{tabular}{|c|c|c|c|c|c|c|}
\hline $\mathrm{AoA}\left({ }^{\circ}\right)$ & $C_{\mathrm{L}}$ & $C_{\mathrm{m}}$ & $C_{\mathrm{L} \alpha}(1 / \mathrm{rad})$ & $C_{\mathrm{m} \alpha}(1 / \mathrm{rad})$ & $C_{\mathrm{Lq}}$ & $C_{\mathrm{mq}}$ \\
\hline-6 & -0.127 & -0.087 & 4.353 & -0.409 & 4.750 & -7.734 \\
\hline 0 & 0.329 & -0.130 & 4.344 & -0.391 & 4.768 & -7.777 \\
\hline 1.87 & 0.471 & -0.142 & 4.323 & -0.382 & 4.772 & -7.773 \\
\hline 3 & 0.555 & -0.150 & 4.307 & -0.375 & 4.774 & -7.766 \\
\hline 6 & 0.780 & -0.169 & 4.247 & -0.355 & 4.778 & -7.734 \\
\hline
\end{tabular}




\subsection{Structural model and analysis}

It was noted in previous research that the gust response and aeroelastic requirement become more critical concern than structural strength against maneuver load for the wing structure design of a small aircraft such as UAV [21]. To focus on the primary objective of the present study, the flying-wing structure is simplified and modelled as a flat panel made of composite pre-preg HexPly M56-IM7. The wing structure is made of laminated composite with quasi-isotropic layup of 40 plies [(45/90/$\left.45 / 0 / 45 / 0)_{2} /(-45 / 0 / 45 / 0)_{2}\right]_{\mathrm{s}}$ and total thickness $10 \mathrm{~mm}$. The structure is modelled by finite element method (FEM) using Nastran software package. When applying the aerodynamic force (Fig.3b) under limit load (2.5g) onto the wing model, the maximum micro strain is $2140 \mu \varepsilon$ in the kink region between the outer and inner wing as shown in Fig.4. The maximum deflection occurring at the wingtip is $0.26 \mathrm{~m}$. The results indicate that there is a large safety margin for structure weight saving that can be achieved by optimizing the skin thickness or tailoring the laminate layup [22-23] to reduce gust response and increase flutter speed.

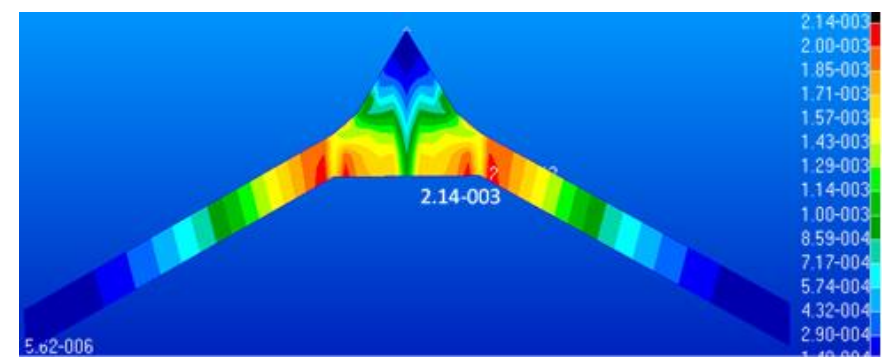

Figure 4. Strain plot of the wing structure subjected to limit load

\subsection{Modal, flutter and gust response of the baseline aircraft}

The analysis results show that the rigid body heave and pitching motion (short period mode) of the baseline aircraft model is $0.5 \mathrm{~Hz}$ and $0.4 \mathrm{~Hz}$ respectively at flight speed $V=20 \mathrm{~m} / \mathrm{s}$. As the flight speed increases to $V=50 \mathrm{~m} / \mathrm{s}$, the short period frequency increases to $1.0 \mathrm{~Hz}$. The first four symmetric modes of the flexile aircraft structure to include in the flutter analysis are shown in Fig. 5.

Based on the modal results and unsteady aerodynamic analysis using Doublet-Lattice method, aeroelastic analysis of the baseline aircraft was carried out. In the classical case, the wing is clamped at the root (aircraft center line) to restrict the rigid-body motion. The resulting flutter speed is $V_{\mathrm{f}}=145.2 \mathrm{~m} / \mathrm{s}$ with flutter frequency $6.74 \mathrm{~Hz}$. In the body freedom flutter (BFF) analysis however, the rigid body motion is set free and the first four elastic body modes were included. The resulting BFF speed is dramatically reduced to $V_{\mathrm{f}}=54.6 \mathrm{~m} / \mathrm{s}$ as shown in the $V$-g plot in Fig. 6(a) although $V_{\mathrm{f}}>1.2 V_{\mathrm{D}}$ still satisfies the design requirement in compliance with the CS-VLA. The associated flutter frequency 
is $f_{\mathrm{f}}=2.9 \mathrm{~Hz}$. The $V$ - $f$ result as shown in Fig. 6(b) indicates that the 1 st and 2 nd bending modes are coupled with the short period oscillation (rigid-body pitching) mode (RP) in the BFF phenomenon.

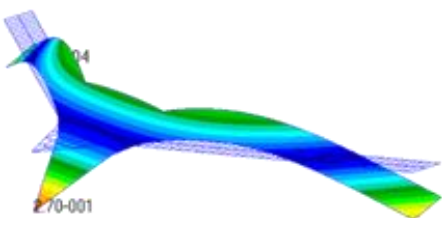

(a) $1^{\text {st }}$ bending mode $1.65 \mathrm{~Hz}$

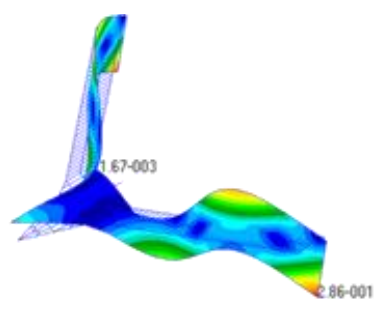

(c) $1^{\text {st }}$ torsion mode $8.18 \mathrm{~Hz}$

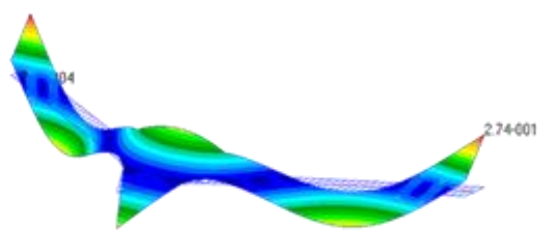

(b) $2^{\text {nd }}$ bending mode $4.19 \mathrm{~Hz}$

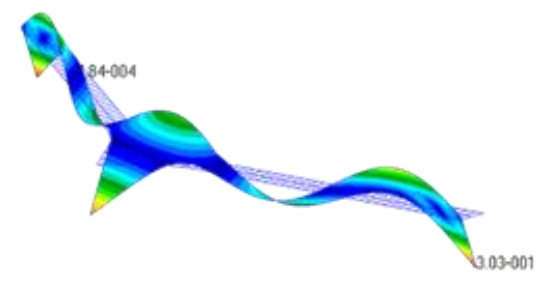

(d) $3^{\text {rd }}$ bending mode $10.07 \mathrm{~Hz}$

Figure 5. The first four symmetric mode shapes of the flying-wing structure
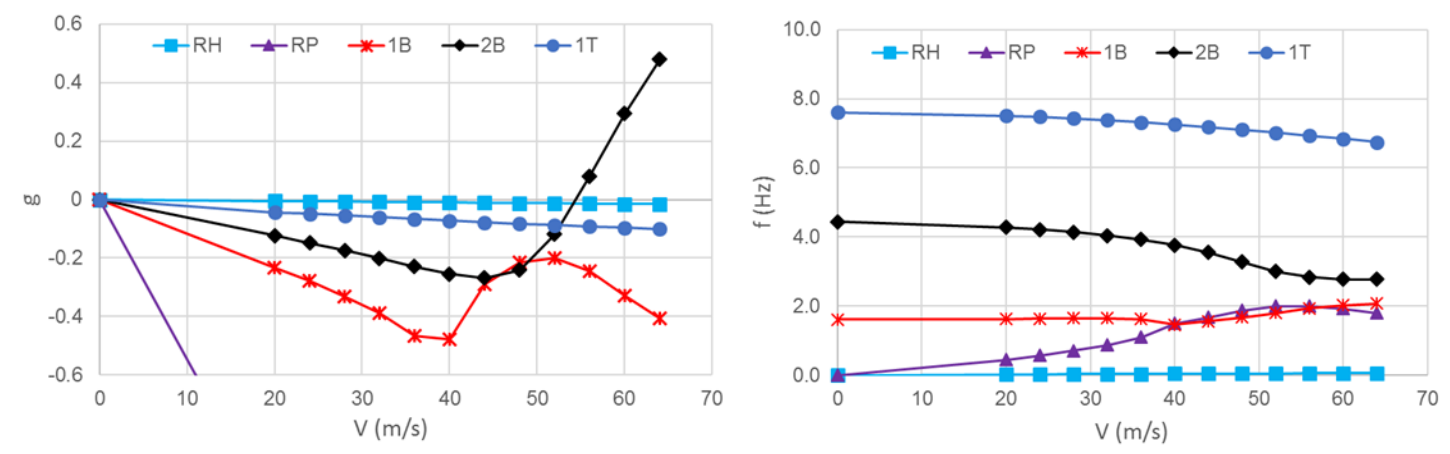

Figure 6. (a) The BFF V-g plot and (b) V-f plot of the baseline flying-wing aircraft

For gust response, the specified design gust velocity are $U_{\mathrm{de}}= \pm 15.24 \mathrm{~m} / \mathrm{s}$ at $V_{\mathrm{c}}$ and $U_{\mathrm{de}}= \pm 7.62 \mathrm{~m} / \mathrm{s}$ at $V_{\mathrm{D}}$ according to the CS-VLA for a very light aircraft design. Since the design gust velocity $U_{\mathrm{de}}= \pm 15.24 \mathrm{~m} / \mathrm{s}$ at $V_{\mathrm{c}}=30 \mathrm{~m} / \mathrm{s}$ (see Table 1 ) is double of the $U_{\mathrm{de}}$ at $V_{\mathrm{D}}=40 \mathrm{~m} / \mathrm{s}$, it is more critical hence selected in the current investigation. Initially, three different gust gradients $L_{g}=7.64 \mathrm{~m}, 11.25 \mathrm{~m}$ and $15.0 \mathrm{~m}$, which are equivalent to flight distance at $0.25 \mathrm{~s}, 0.375 \mathrm{~s}$ and $0.5 \mathrm{~s}$ at $V_{\mathrm{c}}$ respectively were considered to evaluate the gust response. The corresponding equivalent gust frequencies $f_{\mathrm{g}}=1.96 \mathrm{~Hz}$, $1.33 \mathrm{~Hz}$ and $1.0 \mathrm{~Hz}$ respectively are within the range of the aircraft short period oscillation and wing $1^{\text {st }}$ bending mode. The CS-VLA specified typical gust gradient $L_{g}=12.5 \bar{C}=7.64 \mathrm{~m}\left(2 L_{g}=25 \bar{C}\right)$ as shown in $\mathrm{Eq}(6)$ is inclusive. The gust load was calculated based on Eq.(7) with the same spanwise aerodynamic distribution as shown in Fig.3(b). The gust response results are shown in Fig.7 in terms of the wing deflection at the location $\mathrm{y}=3.738 \mathrm{~m}$ (see Fig.2) and bending moment (BM) at the root of the outer wing $(\mathrm{y}=0.962 \mathrm{~m})$. 


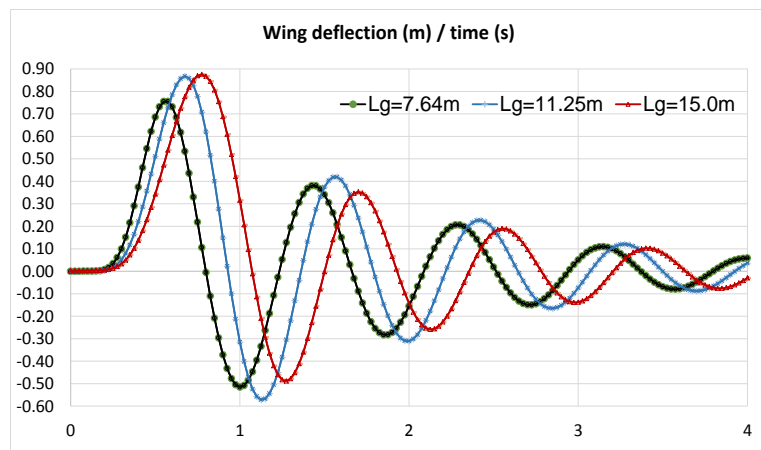

(a)

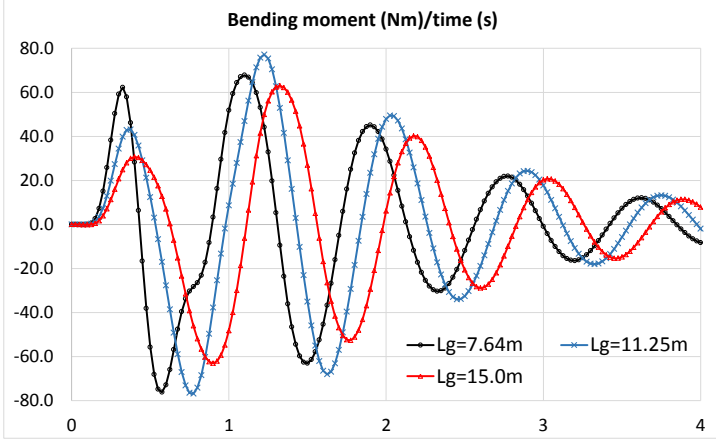

(b)

Figure 7. (a) The wing deflection (b) BM of the baseline aircraft in response to the gust loads

The results in Fig.7 show that the maximum bending moment $(-76.1 \mathrm{Nm})$ produced by the gust load at $f_{g}=1.96 \mathrm{~Hz}\left(L_{g}=7.64 \mathrm{~m}\right)$ is almost the same as that $(-76.8 \mathrm{Nm})$ at $f_{\mathrm{g}}=1.33 \mathrm{~Hz}\left(L_{g}=11.25 \mathrm{~m}\right)$ although the deflection is slightly larger for the latter. In addition to the above cases, a particular gust frequency $f_{\mathrm{g}}=1.65 \mathrm{~Hz}$ that coincides with the wing $1^{\text {st }}$ bending mode raised a concern. Since the $f_{\mathrm{g}}=1.65 \mathrm{~Hz}$ is between the above two cases $\left(f_{\mathrm{g}}=1.33 \mathrm{~Hz}\right.$ and $\left.1.96 \mathrm{~Hz}\right)$ of maximum gust response, it is not expected to have a significantly greater gust response in this case. To clarify this concern however, the gust responses to this particular gust load at $f_{\mathrm{g}}=1.65 \mathrm{~Hz}$ is calculated. The resulting wing deformation and bending moment are compared with the typical gust case $\left(L_{g}=7.64 \mathrm{~m}\right)$ specified by CS-VLA and shown in Fig. 8.
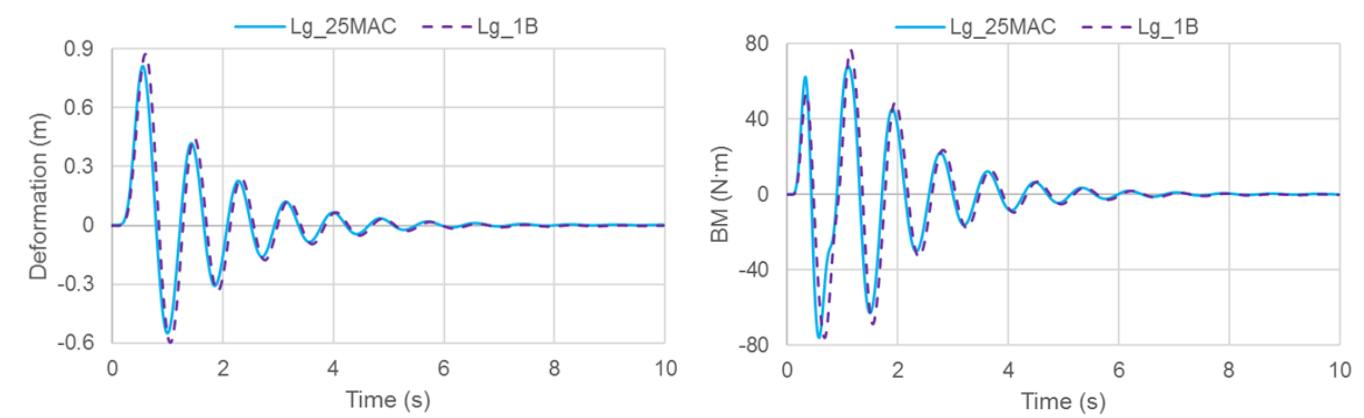

Figure 8. (a) The wing deflection and (b) bending moment in response to the typical gust ( $\left.\mathrm{L}_{\mathrm{g} \_} 25 \mathrm{MAC}\right)$ and the gust of the wing $1^{\text {st }}$ bending frequency $\left(\mathrm{L}_{\mathrm{g} \_} 1 \mathrm{~B}\right)$

It is noted that the wing deforms almost in phase with the input gust load, hence the maximum deflection occurs in almost the same time as the gust peak velocity at $t=0.6 \mathrm{~s}$ for this particular gust $\left(f_{\mathrm{g}}=1.65 \mathrm{~Hz}\right)$. The maximum bending moment $(\mathrm{BM})$ occurs later in the $2^{\text {nd }}$ and $3^{\text {rd }}$ peak response cycle due to the influence of inertia force and higher order modes of the wing. It is also noted that the two most concerned gust frequencies result in almost the same response value. Therefore the gust load at $f_{\mathrm{g}}=1.96 \mathrm{~Hz}$ corresponding to the typical gust length $2 L_{\mathrm{g}}=25 \bar{C}$ specified in the CS-VLA is selected. The 
gust response is taken as the reference results of the baseline aircraft for the PGAD evaluation and its influence on the BFF of the aircraft in the following investigation.

\section{Flutter and Gust Response of the Wing with the PGAD}

For the aircraft with the PGAD, all the details remain the same as the baseline aircraft except the wingtip section to be replaced by the PGAD as shown in Fig. 9. It is a separate segment of the same airfoil and area as the wingtip section defined in the baseline aircraft shown in Fig. 2. The PGAD length of $0.287 \mathrm{~m}$ is $7 \%$ of the wing semi-span and connected to the outer wing spar through a shaft at $0.1 c(10 \%$ chord $)$ location.

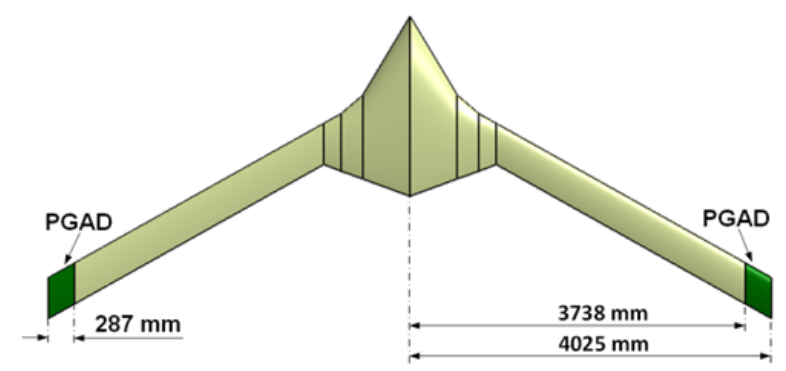

(a)

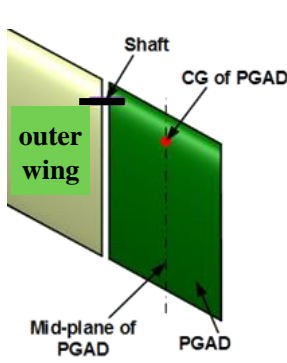

(b)

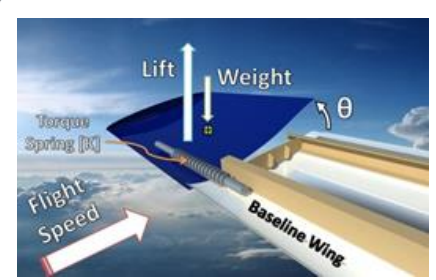

Figure 9. (a) the aircraft with the PGAD location (b) details of the PGAD

\subsection{The PGAD key parameters}

Given a shaft location normally in line with the wing front spar, the PGAD mass, location of the center of gravity (CG) and spring torsional stiffness are three key parameters for the PGAD design. The optimal parameters depend upon the aircraft configuration, modal and aeroelastic behavior. A detailed parametric study on the PGAD design for a conventional aircraft can be found in previous research [12]. The current study was focused on the effect of the three key parameters on the gust response and BFF of the aircraft in comparison with the baseline aircraft model.

To set a reference design case, the PGAD CG location remains the same as the baseline aircraft at $0.15 c$. The torque spring stiffness is set as $100 \mathrm{Nm} / \mathrm{rad}$. In this case, the gust induced wing bending moment $(\mathrm{BM})$ is reduced by $15.9 \%$ and the BFF speed of the aircraft is increased to $56.9 \mathrm{~m} / \mathrm{s}$ (by $4.2 \%$ from the baseline $V_{\mathrm{f}}=54.6 \mathrm{~m} / \mathrm{s}$ ) as shown in Fig. 10(a). When reducing the PGAD mass by $2 \mathrm{~kg}$ from $3.25 \mathrm{~kg}$ to $1.25 \mathrm{~kg}$ however, the BM is almost doubled (-99\% reduction) and the BFF speed is decreased to $44.5 \mathrm{~m} / \mathrm{s}$. When increasing the PGAD mass to $5.25 \mathrm{~kg}$ and $7.25 \mathrm{~kg}$ respectively, both the BM and BFF speed become a little better or worse by less than $3 \%$ from the reference design case. The results indicate that the gust response and BFF are much more sensitive and reduce with the PGAD mass reduction below $3.25 \mathrm{~kg}$. The baseline PGAD mass offers an optimal option and therefore adapted in the subsequent study. 
Based on the above reference case where spring stiffness remains as $100 \mathrm{Nm} / \mathrm{rad}$, the results indicate that the PGAD CG location shifting forward has positive effect on both the gust induced BM and BFF speed. As shown in Fig. 10(b), when shifting the PGAD CG forward from $15 \%$ to $10 \%$ and $5 \%$ chord respectively, the $\mathrm{BM}$ is reduced significantly by $20.4 \%$ and $36.8 \%$ respectively while the BFF speed has negligible decrease. As opposed to above, the BM is increased by $13.3 \%$ and $61.2 \%$ respectively when shifting the PGAD CG location backward to $30 \%$ and $45 \%$ chord respectively; and the BFF speed decreased significantly to $46.5 \mathrm{~m} / \mathrm{s}$ and $41.5 \mathrm{~m} / \mathrm{s}$ respectively as shown in Fig. 10(b). Although the results indicate that shifting the CG forward would be more effective for gust load reduction, the $15 \%$ chord location is adapted considering the feasibility in practice.

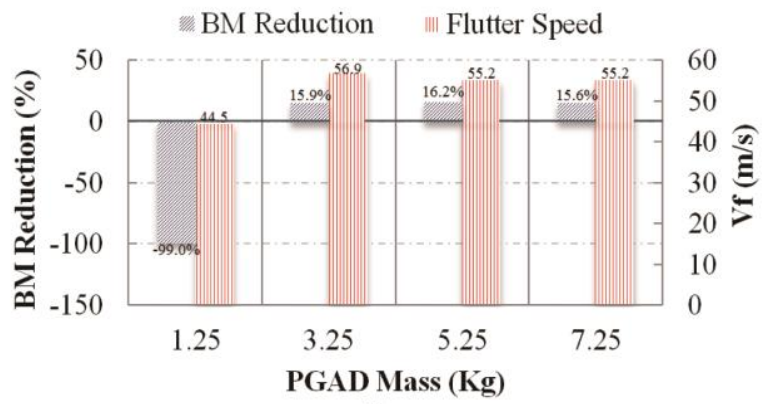

(a)

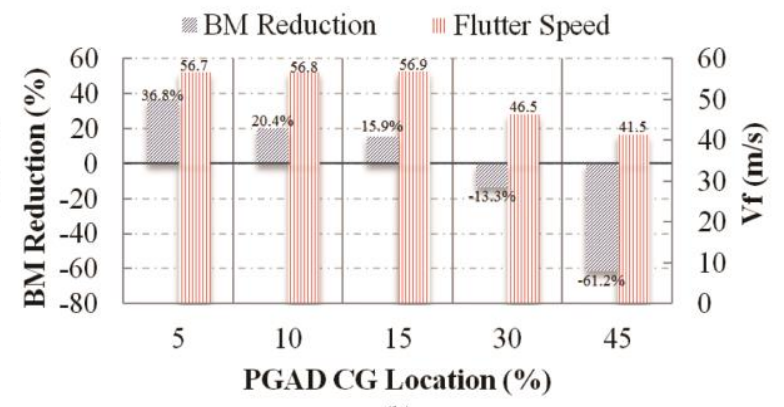

(b)

Figure 10. Variation of the BM and flutter speed with the (a) PGAD mass and (b) the CG location

To evaluate the effect of PGAD spring stiffness on gust response and BFF, the PGAD mass 3.25 $\mathrm{kg}$ and $\mathrm{CG}$ location at $15 \%$ chord remain the same as the above case. As shown in Fig. 11, the spring stiffness reduced to $50 \mathrm{Nm} / \mathrm{rad}$ leads to a significant increase (negative reduction) of BM and decrease of BFF speed. When the stiffness is increased to $175 \mathrm{Nm} / \mathrm{rad}$, the BM is reduced by $17.5 \%$, but the BFF speed is decreased a little to $56.1 \mathrm{~m} / \mathrm{s}$ comparing with the spring stiffness $100 \mathrm{Nm} / \mathrm{rad}$. Further increase the stiffness leads to less effective PGAD and eventually convergence to the baseline aircraft results when the stiffness is increased to the same torsional stiffness as the baseline wingtip section.

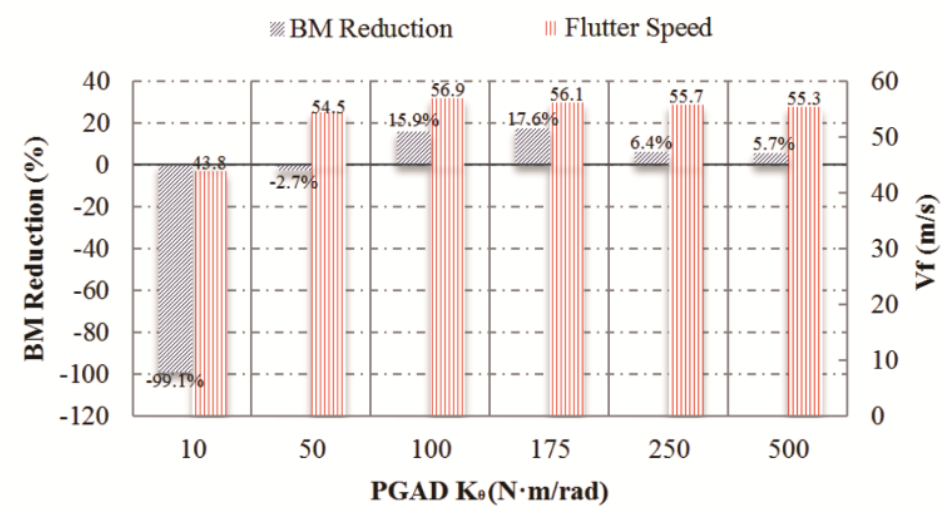

Figure 11. Variation of the BM and BFF speed with the PGAD spring stiffness 
The above parametric study shows a narrow band of optimal PGAD parameters that have significant beneficial effect on both gust load alleviation and BFF. For example, the spring stiffness from $100 \mathrm{Nm} / \mathrm{rad}$ to $200 \mathrm{Nm} / \mathrm{rad}$ combined with the PGAD mass over $3.25 \mathrm{~kg}$ and CG location forward of $15 \%$ chord would result in a gust load reduction over $18 \%$ with BFF speed meeting the CS-VLA requirement. In this investigation, the set of optimal PGAD parameters shown in Table 3 is selected to further the analysis of the PGAD function for gust alleviation and BFF suppression.

Table 3. Initial design data of the PGAD

\begin{tabular}{|l|c|c|c|c|}
\hline $\begin{array}{c}\text { PGAD } \\
\text { surface area }\end{array}$ & $\begin{array}{c}\text { PGAD } \\
\text { mass }\end{array}$ & $\begin{array}{c}\text { Spring } \\
\text { stiffness }\end{array}$ & $\begin{array}{c}\text { Shaft } \\
\text { location }\end{array}$ & $\begin{array}{c}\text { CG } \\
\text { location }\end{array}$ \\
\hline $0.1306 \mathrm{~m}^{2}$ & $3.25 \mathrm{Kg}$ & $100 \mathrm{Nm} / \mathrm{rad}$ & $0.1 c$ & $0.15 c$ \\
\hline
\end{tabular}

\subsection{Modal and flutter analysis}

Further analysis of the aircraft BFF is carried out based on a set of optimal PGAD key parameters as listed in Table 3. The short oscillation frequency of the aircraft remains the same as the baseline. The first five modes of the aircraft wing including the PGAD are calculated and shown in Fig. 12.

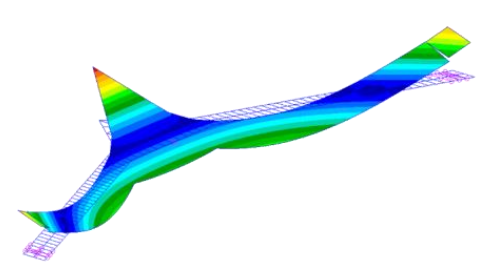

(a) $1^{\text {st }}$ bending mode $1.61 \mathrm{~Hz}$

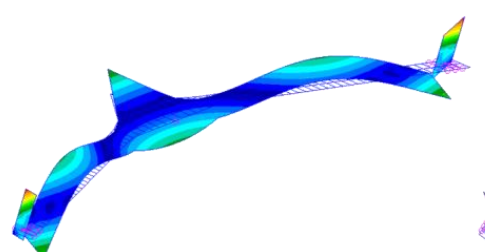

(c) $2^{\text {nd }}$ bending mode $5.03 \mathrm{~Hz}$

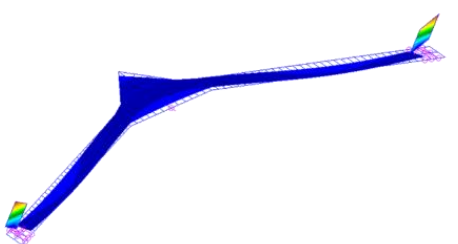

(b) PGAD twist mode $3.57 \mathrm{~Hz}$

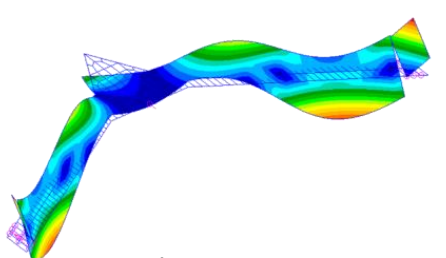

(d) $1^{\text {st }}$ torsion mode $7.49 \mathrm{~Hz}$

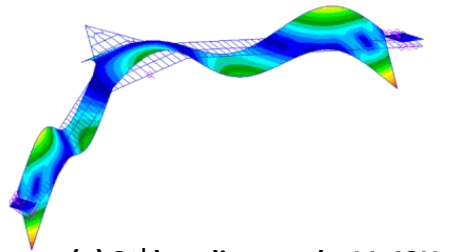

(e) $3^{\text {rd }}$ bending mode $11.43 \mathrm{~Hz}$

Figure 12. The first four symmetric mode shapes of the flying-wing structure

In the aeroelastic analysis, the short period, PGAD and the first four elastic body modes were included. The resulting body free flutter (BFF) speed is $56.9 \mathrm{~m} / \mathrm{s}$ with flutter frequency $2.8 \mathrm{~Hz}$. The resulting $V$ - $g$ and $V$-f plots are shown in Fig. 13. It is noted that the $1^{\text {st }}$ bending mode coupled with the 
PGAD mode is the dominating modes for the primary flutter speed. Comparing with the baseline aircraft, the flutter speed of the aircraft with PGAD is increased by $12.5 \%$.

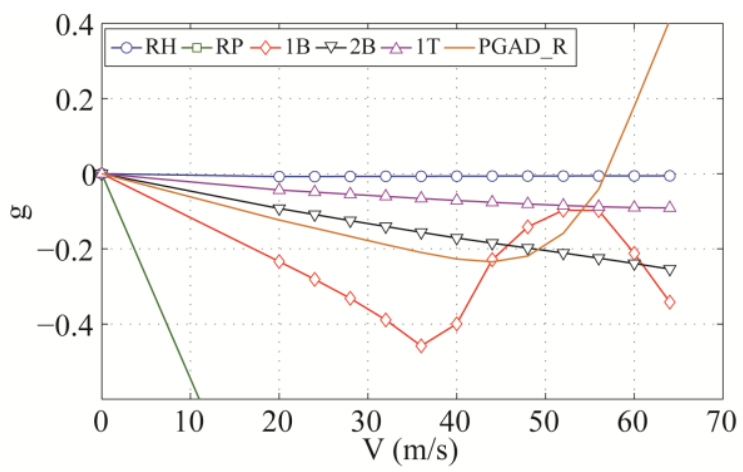

(a)

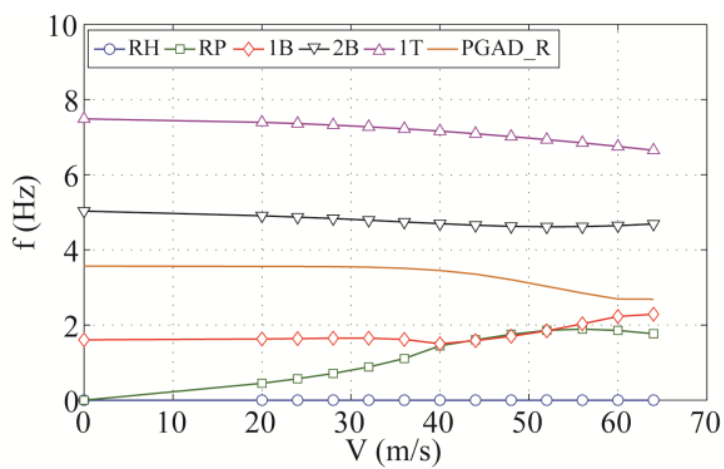

(b)

Figure 13. (a) The BFF $V-g$ plot (b) $V-f$ plot of the flying-wing aircraft with PGAD

\subsection{Gust response analysis}

In the gust response analysis, the flight speed $V_{\mathrm{c}}$ and gust velocity and the typical gust gradient associated with $f_{\mathrm{g}}=1.96 \mathrm{~Hz}$ remain the same as the baseline case. The input gust velocity and the corresponding PGAD twist angle relative to the outer wing section at $y=3.783 \mathrm{~m}$ is shown in Fig.14. In response to the gust, the PGAD initially twisted in a small negative angle (nose down) against the gust load in the first half cycle before the gust peak value. When the gust velocity reduced in the second half cycle after the peak value, the PGAD twisted in a positive 3.2 degree in phase with the gust velocity. This is mainly due to the reaction of the PGAD inertia and the spring elastic recovery force. After the gust excitation period, the PGAD vibration is gradually damping out.

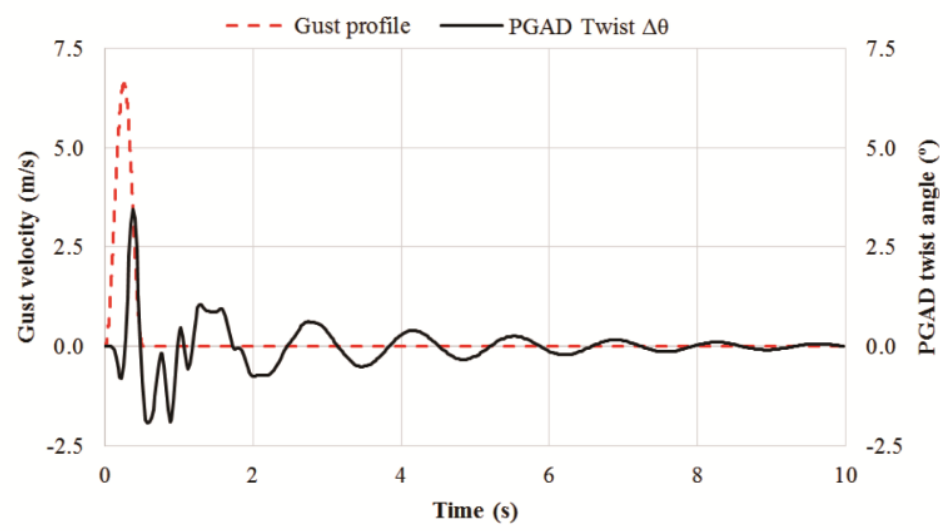

Figure 14. Gust velocity and corresponding PGAD twist angle

The resulting gust response in terms of wing deflection and bending moment (BM) is presented in Fig. 15(a) and Fig. 15(b) respectively in comparison with the baseline aircraft. The wing deformation was 
calculated at the same location as the baseline aircraft $(y=3.783 \mathrm{~m})$ and the bending moment $(\mathrm{BM})$ at the root of outer wing section $(y=0.962 \mathrm{~m})$. The results indicate that the maximum wing deformation $(0.556 \mathrm{~m})$ and the maximum BM $(64.06 \mathrm{Nm})$ is reduced by $31.2 \%$ and $15.9 \%$ respectively comparing with the results of the baseline aircraft. The results also show that the gust response of the aircraft with the PGAD is slower at a lower frequency than the baseline aircraft.

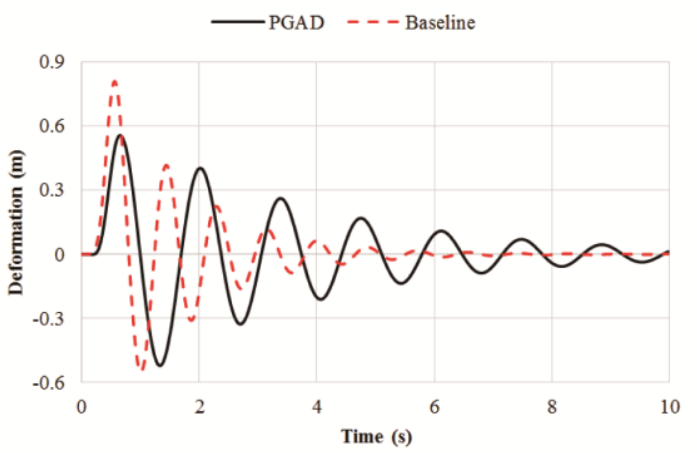

(a)

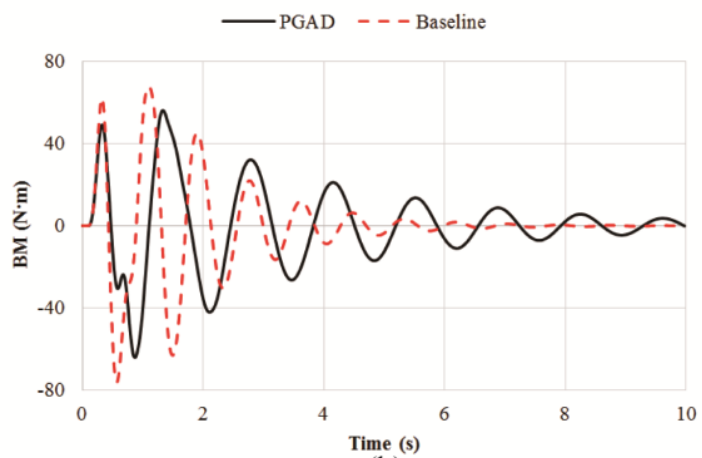

(b)

Figure 15. (a) Gust response in terms of wing deformation (b) the bending moment at wing root

However the results also indicate that after the gust input period, the subsequent gust response especially the second peak of deformation and BM in negative values remains in a large value. In order to reveal the PGAD function, the resulting BM and the PGAD twist angle are calculated and presented in Fig. 16. As the result of the PGAD's first twist in a small negative angle, the PGAD produces a negative (downward) aerodynamic force. The reduction of the wing BM due to the PGAD twist is shown in Fig. 15(b) and Fig. 16. As the result of the subsequent PGAD negative twist, the corresponding BM is reduced for the same reason.

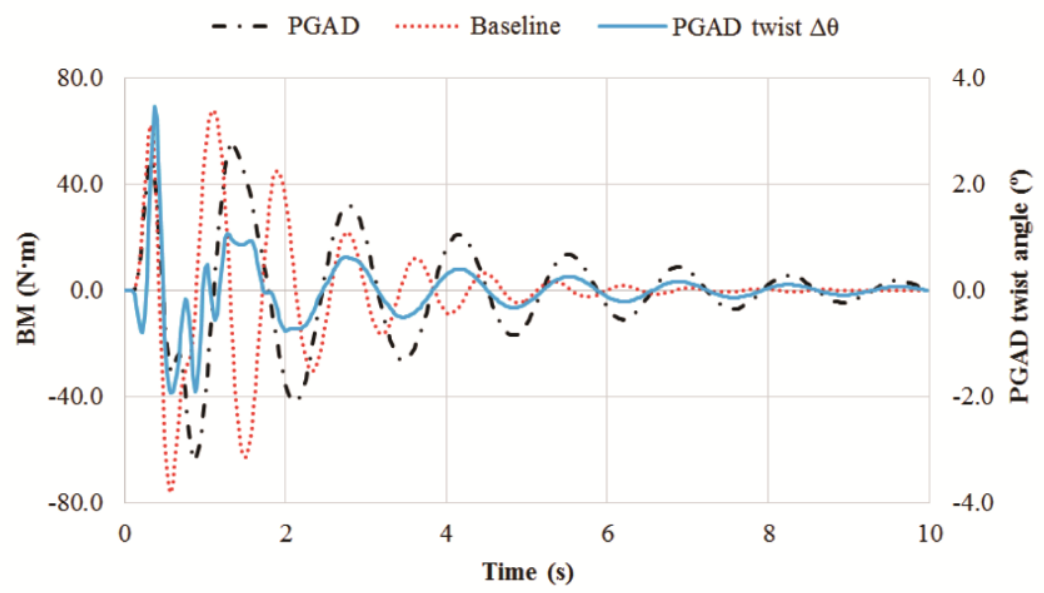

Figure 16. Gust response in terms of bending moment and PGAD twist angle 
It is noted however that the gust response in the first a few cycles within $2 s$ time is also reduced significantly even though the PGAD twists in positive angle. This result seems conflict with the PGAD primary function that positive twist should produce positive aerodynamic force on the wing rather than gust alleviation. In order to clarify the query, the pitching angle at the aircraft CG in response to the PGAD twist is calculated and shown in Fig.17.

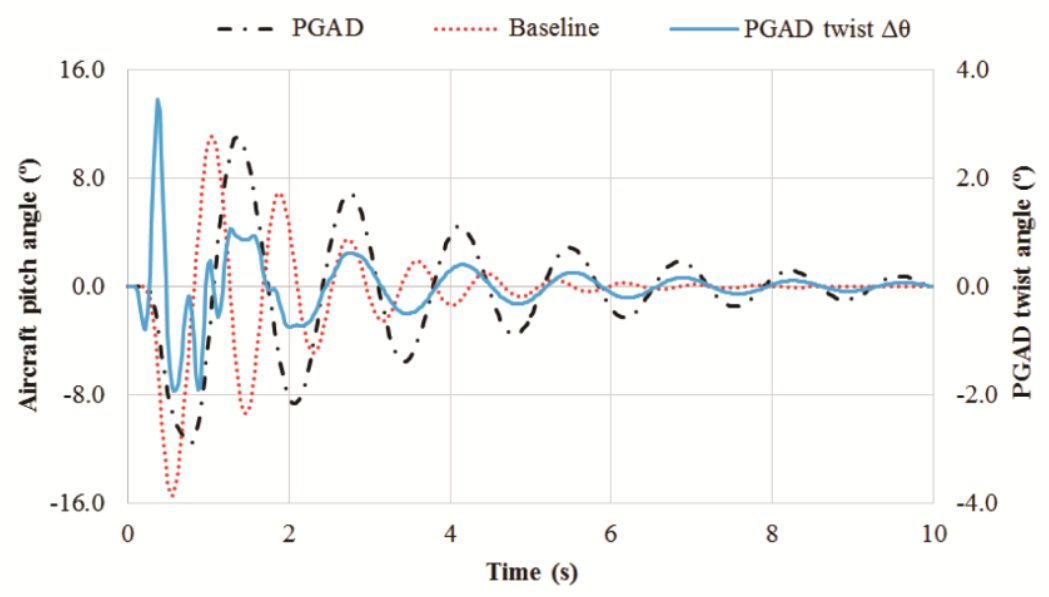

Figure 17. The aircraft pitching angle and PGAD twist angle in response to the gust

It is observed that when the PGAD twists in positive angle, the corresponding aircraft pitches in negative angle (nose down). This is because the PGAD plays partly the role of tail-plane that produces negative pitching moment acting on the flying-wing aircraft. This negative pitching motion of the aircraft results in a reduction of aerodynamic force especially within $2 \mathrm{~s}$ when the maximum BM occurs as shown in Fig.17. When the PGAD positive twist angle reduces after 2s, its primary function as part of the wing dominates the gust response so that the BM remains in a relatively large value.

\section{Conclusions}

A flying-wing aircraft of high aspect ratio and large swept angle flexible wing is prone to gust and body freedom flutter (BFF) due to aeroelastic coupling between short period pitching oscillation and wing bending modes. In this investigation, a very light flying-wing aircraft model has been taken as an example to evaluate the PGAD effectiveness for gust load alleviation and BFF suppression. In response to gust load, the PGAD mounted at the wingtip plays a mixed role of partly a piece of wing surface and partly tail-plane. There is an optimal combination for the PGAD mass, CG location and spring stiffness to be beneficial to both gust alleviation and BFF. The optimal PGAD contributes to gust alleviation in the role of wing control surface when it twists out-of-phase to the gust velocity and in the role of tail-plane when it twists in-phase with the gust. The results from one set of the PGAD optimal design parameters show that significant gust alleviation has been obtained in terms of wing 
deformation reduction by $31 \%$ and BM reduction by $16 \%$. In addition, the optimal PGAD results in an increase of BFF speed by $4.2 \%$ in comparison with the baseline the aircraft.

\section{Acknowledgments}

The authors thank the USAF European Office of Aerospace Research and Development (EOARD) and Chinese Scholarship Council for financial support to this research. We also thank Prof. O. Sensburg in Cranfield University and Dr. Raymond Kolonay in USAF AFMC AFRL for their technical advice.

\section{References}

1. S Guo, W Cheung, JR. Banerjee and R Butlar, Gust alleviation and flutter suppression of an optimised composite wing, presented and published in Proc. of the International Forum on Aeroelasticity and Structural Dynamics, Manchester, U.K. June 1995, pp.41.1-41.9

2. Britt, R., Jacobson, S., Arthurs, T, “Aeroservoelastic analysis of the B-2 bomber" Journal of Aircraft Vol 37, No. 5. September-October 2000

3. GregoryW. Reich, Daniella E. Raveh, and P. Scott Zink, Application of active-aeroelastic-wing technology to a joined-wing sensorcraft, Journal of Aircraft, Vol. 41, No. 3, May-June 2004.

4. Karpel M., Moulin B., Chen P. C., Dynamic Response of Aeroservoelastic Systems to Gust Excitation. Journal of Aircraft, 42(5), 2005, 1264-1272.

5. Roesch P., Harlan R. B., A passive gust alleviation system for light aircraft. AIAA 74-773. 1974.

6. Eric Vartio, Anthony Shimko, Carl P. Tilmann, Peter M. Flick, Structural modal control and gust load alleviation for a sensorcraft concept, the 46th AIAA/ASME/ASCE/AHS/ASC Structures, Structural Dynamics \& Materials Conference, 18 - 21 April 2005, Austin, Texas AIAA 2005-1946

7. Mardanpour, P., Izadpanahi, E., Rastkar, S., and Hodges, D. H., Effects of Engine Placement on the Nonlinear Aeroelastic Gust Response of High-Aspect-Ratio Wings, AIAA Modeling and Simulation Technologies Conference, AIAA SciTech Forum, (AIAA 2017-0576)

8. Robert T. Britt, Thomas D. Arthurs, Steven B. Jacobson, Aeroservoelastic Analysis of the B2 Bomber, Journal of Aircraft 37(5): September 2000, 745-752

9. Sergio Ricci, Politecnico di Milano, Michele Castellani, Giulio Romanelli, Multi-Fidelity Design of Aeroelastic Wing Tip Devices, Proceedings of the institution of mechanical engineers, Part G Journal of Aerospace Engineering 227(10): 1596-1607 Sept 2012.

10.Miller S., Vio G. A., Cooper J. E., et al., 2008. Optimisation of a scaled sensorcraft model with passive gust alleviation. AIAA 2008-5875.

11.S. Guo, Q. Fu, O.K. Sensburg, Optimal Design of a Passive Gust Alleviation Device for a Flying Wing Aircraft, 12th AIAA ATIO/14th AIAA/ISSMO MAO Conference, Session MAO-25, Indianapolis, Indiana, USA, 17-19 Sept. 2012

12.Guo S., Monteros J., Liu Y., 2015. Gust alleviation of a large aircraft with a passive twist wingtip. Aerospace, 2(2), 135-154.

13.Chipman R., Rauch F., Rimer M., et al., 1984. Body-freedom flutter of a 1/2 scale forward-sweptwing model, an Experimental and Analytical Study. NASA CR-172324.

14. Love M. H., Zink P. S., Wieselmann P. A., 2005. Body freedom flutter of high aspect ratio flying wings. AIAA 2005-1947.

15. Jacobson S.B., Britt R. T., Dreim D. R., et al., 1998. Residual Pitch Oscillation Flight Test and Analysis on the B-2 Bomber. AIAA-98-1805, 39 ${ }^{\text {th }}$ AIAA/ASME/ASCE/AHS/ASC Structures, Structural Dynamics, and Materials Conference and Exhibit, Long Beach, CA, US, 1998

16. EASA Certification Specifications for Very Light Aircraft, March 2009, www.easa.europa.eu/ system/files/dfu/CS-VLA 
17. Frederic M. Hoblit, Gust Load on Aircraft: Concepts and Applications, AIAA Education Series, ISBN: 978-0-930403-45-4, 1988

18. http://web.mit.edu/drela/Public/web/avl

19. Mardanpour, P., Hodges, D., Neuhart, R., and Graybeal, N., Engine placement effect on nonlinear trim and stability of flying wing aircraft. Journal of Aircraft, Vol. 50 No.6, Nov.-Dec. 2013: 17161725 .

20. Mardanpour, P., Richards, P. W., Nabipour, O., and Hodges, D. H., Effect of multiple engine placement on aeroelastic trim and stability of flying wing aircraft," Journal of Fluids and Structures, Vol. 44, 2014, pp. 67-86.

21. M Perera, S Guo, Optimal design of an aeroelastic wing structure with seamless control surfaces, Proc. IMechE, Part G: J. Aerospace Eng. Aug. 2009; vol. 223, 8: pp. 1141-1151.

22. S Guo, W Cheng, D Cui. Aeroelastic tailoring of composite wing structures by laminate lay-up optimization (TN), AIAA Journal, 2006, 44: 3146-3150.

23. S Guo, D. Li, Y. Liu, Multi objective optimization of a composite wing subject to strength and aeroelastic constraints, Proc. IMechE, Part G: J. Aerospace Eng, vol. 226, 9 (2012): 1095-1106. 
2017-08-14

\title{
Gust response and body freedom flutter of a flying-wing aircraft with a passive gust alleviation device
}

\author{
Guo, Shijun
}

Elsevier

Guo S, Jing ZW, Li H, Lei WT, He YY, Gust response and body freedom flutter of a flying-wing aircraft with a passive gust alleviation device, Aerospace Science and Technology, Vol. 70, November 2017, pp. 277-285

http://dx.doi.org/10.1016/j.ast.2017.08.008

Downloaded from Cranfield Library Services E-Repository 